\title{
Physiological Responese Measrement to Identify Online Visual Representation Designs
}

\author{
Yu-Ping Hsu \\ Program of Educational Technology \\ University of Kansas \\ Lawrence, KS, USA
}

\author{
Edward Meyen \\ Department of Special Education \\ University of Kansas \\ Lawrence, KS, USA
}

\author{
Richard Branham \\ Department of Design \\ University of Kansas \\ Lawrence, KS, USA
}

\begin{abstract}
This research involved the identification and validation of text-related visual display design principles from the literature. Representations were designed and developed that illustrated the intent of each visual display design principle included in the study. The representations were embedded in a research intervention and included validated examples of accurate displays of each principle and examples with varying degrees of inaccuracies. The representations were created based on design theories of human cognition: perceptual, attention memory, and mental models [1][2][3][4][5], and presented via a monitor in a controlled research environment. The environmental controls included space appropriate to the experiment, constant temperature, consistent lighting, management of distractions including sound, monitoring of operation of the measurement device and the use of standardized instructions. Bertin's seven visual variables: position, size, color, shape, value, orientation and texture, were also examined within the design principles [6]. The result of the independent samples $t$ test did not find significant differences between good and poor visual designs for all images across subjects. However, the results of the paired-samples $t$ test found significant mean differences between Bertin's principles for color, value and orientation of visual designs across subjects. The findings support future online instructional designs and investigate the implications for the design of online instruction.
\end{abstract}

Keywords-electrodermal activity measurement; digital visual representation design; affective learning

\section{INTRODUCTION}

The transformation of the learning environment, as a consequence of unprecedented growth at all levels of education, has occurred without the benefit of broad based programmatic research. Early research in online instruction focused largely on (1) the structuring of content, (2) strategies for the validation of online instructional design elements to enhance instruction, and (3) an approach to instructional accountability. A body of literature raised questions about the quality of online instruction, e.g., retention, student performance, and lack of engagement; there were also issues related to the need for additional research [7][8][9][10]. A more recent interdisciplinary line of research on online instruction resulted in the creation and validation of Universal Designs for Learning (UDL) [11][12]. This research combines education, cognitive neuroscience and technology to fill the gap of visual display design in online instruction. The early evolving pattern of this research has addressed the application of UDL to online instruction as a mode of teaching and learning.
Only a limited amount of early research addressed visual display designs that maximize the impact of text and visual presentations in engaging and motivating online learners. The primary limitation hindering research on motivation and engagement could be the lack of technologies to identify and measure engagement / motivation of learners in real time, online instructional environments. Research studies to date have not sufficiently addressed the instructional value and effectiveness of visual display designs in online teachinglearning environments There needs to be an increased emphasis on researching visual display design principles as applied to the process of learning in online instructional environments. Policy makers have high expectations of technology for supporting learning. This adds to the importance conducting research related to visual display designs.

The work of researchers has identified visual elements that need to be researched [13][14][15][16][17][18]. The effect that visual elements contribute to a student's learning could explain the rapid growth of instructional design; online instruction has gained in popularity due to the influence of technology industries, the commitment of policy makers to the potential of the Internet in instruction. A strong case can be made for the importance of needed research in e-learning to be more interdisciplinary.

The affective experiences of online learners have received less attention than the cognitive development of online instruction. This is largely because the focus of instruction, in all modes of teaching, is on content and learner outcomes aligned with instructional objectives. Therefore, a lack of proven strategies that produce affective outcomes through online instructional design and pedagogy. The lack of significant research measuring emotional responses in online instruction has resulted in assumptions by instructional designers and developers about the engagement of learners in online instruction. These circumstances are changing due to an increase in concern for the motivation and engagement of online learners. For example, an emphasis on analytics as an approach to measuring evidence of involvement and attentiveness has gained in popularity [19][20][21][22].

There have also been advancements in technology for measuring affective outcomes aligned with online instructional experiences. Technologies exists now to measure physiological responses to emotions and to calibrate them with the online instructional stimuli evoking the response [23][24][25]. 
Today, the evidence of involvement and attentiveness is not difficult to measure.

\section{A. $Q$ sensor}

The technology this research employed for measuring emotional responses of online learners was the Q-sensor, which measures and records the physiological responses of learners to verify electrodermal activity (EDA) based on emotional arousal.

\section{B. Research Question}

The research question for this study was:

When representations of evidence-based visual design principles, ranging from explicitly good to explicitly poor examples, are visually displayed in a digital format via the monitor, what measureable physiological responses to the visual representations are consistently emitted by the learner, as measured by the Q-sensor?

\section{Hypotheses}

The hypothesis of this study is related to the research question: The Q Sensor will not measure any significant difference in the digitally formatted electrodermal responses of participants, as they view representations of evidence based visual designs that range from explicit representations of design principles to bad representations.

The purpose of this study was to understand the emotions emitted by college students, in response to viewing online digital representations of evidenced-based visual display design principles. This research study focused on identifying an approach to the design of visual displays for online instruction that enhances positive emotions and engagement of students in studying online.

\section{METHOD}

\section{A. Participants}

The sample was comprised of undergraduate students $(\mathrm{N}=104)$ from a comprehensive mid-western university. A convenience sample approach was employed involving two strategies. The first was the use of an existing system established by a department in the University for recruiting students to serve as participants in research studies. The process involved the submission of a research proposal prepared in accordance with prescribed requirements including the approved IRB. The second was the oral announcement in classes by instructors who agreed to participate in the recruitment of participants.

\section{B. Theoretical Framework}

During the past several decades, psychology, neuroscience, and machine learning theories and research have produced principles of human learning that influence instructional design. Recently, research of human emotions and machine learning environments are leading to change in educational theory and instructional designs of online learning environments [26]. Educational technology is increasingly embodying the principles of social interaction in intelligent tutoring systems to enhance student learning [27]. In the early years, Damasio focused on brain research, and now he suggests that the aspects of cognition that people receive most heavily in schools, namely learning, attention, memory, decision making, and social functioning, are profoundly affected by and subsumed within the processes of emotion [28]. Thus, an important learning research topic is "engagement" and how it relates to learner affect, which becomes emotional expression [29].

The characteristics of emotions are dynamic, individualized, and subjective. Consequently, definitions of emotions may differ depending on the source.. Psychologists make a distinction between emotions and feelings. A feeling is a response to an emotion and related to the experience of a particular situation. Further, an emotion includes interpretation of the situation or experience. The dictionary defines emotions as (a) the affective aspect of consciousness, (b) a state of feeling, (c) a conscious mental reaction (such as anger or fear) subjectively experienced as strong feeling usually directed toward a specific object and typically accompanied by physiological and behavioral changes in the body [28].

The theories on which this study rests connect emotions, learning development and visual display designs. The study highlights the important role of emotional responses in online instructional design, and seeks to understand the relationships between emotional changes and online instructional design elements. Through assessment of emotions during the learning process, the potential exists to expand and validate factors associated with learner engagement though design elements. If these factors are examined together, not only will measurement of emotional response be improved, the results will inspire online learning system designs that make powerful connections with learners and teachers to create a positive online learning experience.

The theoretical framework for this study relies on (a) cognitive psychology perspective of instructional design, (b) human-computer interaction design, (c) visual display design, and (d) human learning development (Figure 1). The theoretical framework explains an approach to understanding the connections between visual design elements and emotional response via the screen. Furthermore, an extension of this approach is the design of "affective online learning environments" for students (Figure 2).

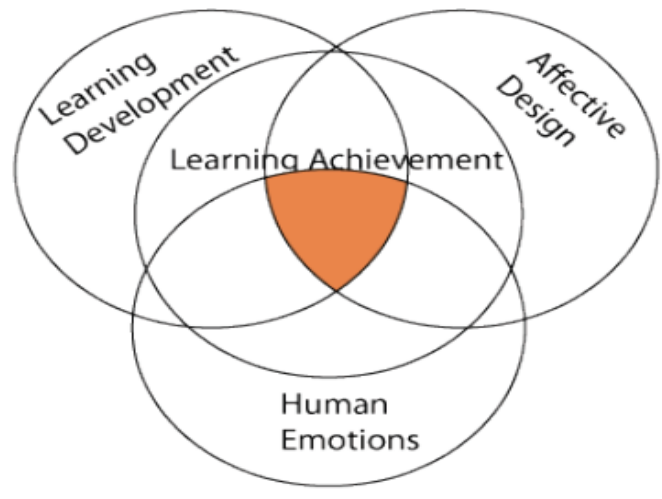

Fig. 1. The Theoretical Framework 


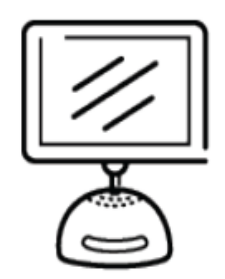

Environments

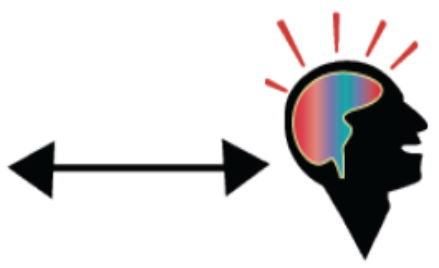

Humans

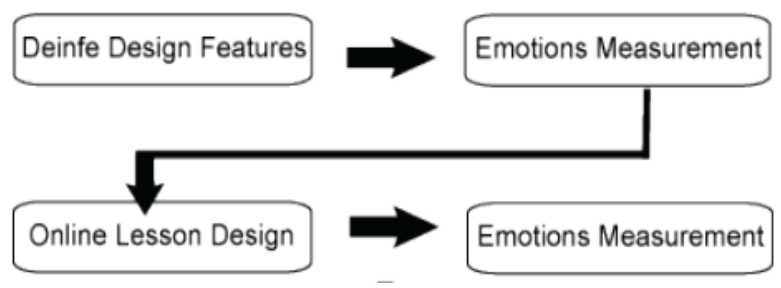

Fig. 2. Affective Online Learning Environment

\section{Procedures}

The experimental intervention consisted of a series of images that were representations of selected visual display design principles. The representations were presented to research participants via a computer monitor. Participants' electrodermal activity (EDA) responses were recorded by the $\mathrm{Q}$ Sensor. The development process for the final research interventions (Figure 3) included the following steps:

- The number of images was 108 (6 sets: letter, words, sentences, simple image, completed image and detail image).

- A standard instruction was given before the practice session.

- A practice session was added. This session involved the presentation of 6 images. The practice session took 34 seconds.

- In the experimental session, the groups of images were exposed for 2 seconds with an interval time between images of 4 seconds. Between the sets of images, there was a pause of 6 seconds. The entire experimental session took about 15 minutes.

- A cool down session was added before all images were shown. This was a period of time for relaxation by the participant with no experimental presentation of images. The cool down session involved the participant being exposed to a blue blank background screen with music for 1 minute and 25 seconds.

- Images within each set were randomized but the sequence of the sets was held constant.

- The entire experiment was timed as 16 minutes 43 seconds. This includes the practice and cool down sessions.

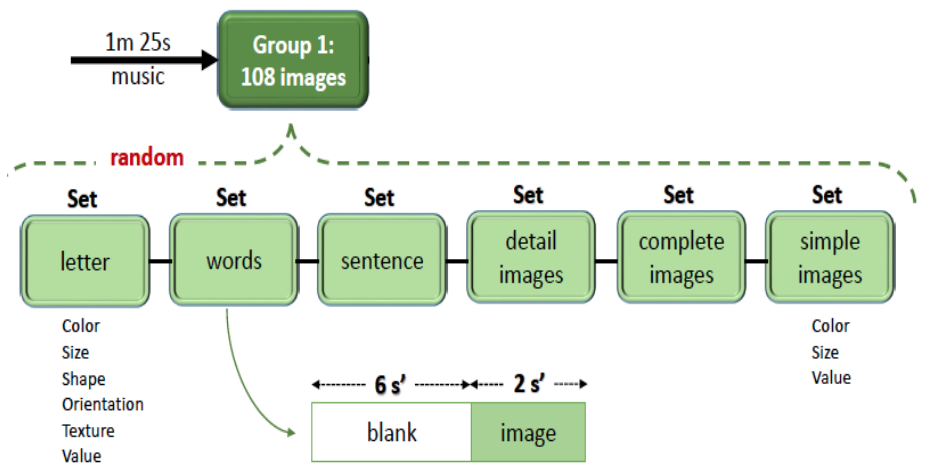

Fig. 3. The Procedure of The Intervention System

\section{Experimental Conditions}

A room was dedicated as space for conducting the experiment. The room was $11^{\prime}$ by $11^{\prime}$ and located in an area where traffic, noise, illumination and temperature could be controlled. There were no windows. As a further initiative to control traffic, signs were placed inside and outside the research suite indicating that an experiment was underway. The furnishings were selected to represent what might be a typical study area and included a desk, office chair, side chair, book case, and picture on the wall behind the desk where participants sat while engaged in the experiment. The same MacBook Pro with a 17" monitor was used to present the intervention to all participants. The position of the computer on the desk was the same for all participants but participants were allowed to adjust the placement of the computer if needed (Figure 4).

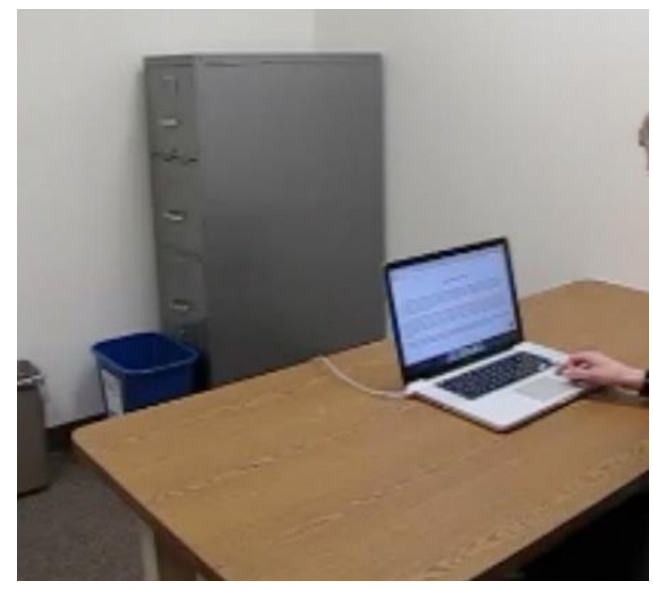

Fig. 4. The Experimental Room

\section{E. Data Analysis}

There is no universally agreed on method for electrodermal activity data analysis. Electrodermal Activity (EDA) data was exported from the Q-sensor 2.0 into CSV files and was collected when the participant arrived. The EDA included skin conductance level (SCL) and skin conductance responses (SCRs). 
The data was from sympathetic neuronal activity. SCL is the background tonic and SCRs were rapid phasic components [30]. The raw varying EDA data was smoothed in Ledalab which is a MATLAB based software for the analysis of EDA. Benedek and Kaernbach published approach on the decomposition of superimposed SCRs was not only based on mathematical modelling but also took into account a particular model of the electrodoemal system and solved several SCL and SCR problems [31][32]. The various mathematically based deconvolution methods offer considerable progress in the evaluation of overlapping SCRs, which are very common to stimulus sequences with short inter-stimulus intervals (ISIs) [33]. Integrated skin conductance responses (ISCRs) are raw electrodermal activity data after the decomposition procedure for every image and participant were calculated in Ledalab. The average microsiemens $(\mu S)$ value was considered when the participant was in the cool-down section. Before each image was shown, it was preceded by 6 seconds of a blank screen. The average 6 seconds EDA data became the participants' baseline values. The changes of EDA data, as each image was shown for 2 seconds, was compared to the baseline values. Data plotting was carried out with $\mathrm{R}$. The follow analysis was conducted to understand the effects of visual display designs arousal and effects of the design principles. Simple T-test was used to see the differences between good and bad visual designs. Paired-T test was used to see the differences between principles of visual designs across subjects.

\section{RESULTS}

Preliminary analyses have been completed by MATLAB on the emotional arousal changes individually and across group 1: 108 images, with individual variation. An independentsamples $t$ test determined that there were differences in emotional arousals between good and poor representations. The emotional arousals for good and poor representations were not distributed normally, and homogeneity of variances was violated (Levene's test, $\mathrm{F}=9.982, p=.002<.05$ ). No significant differences in emotional arousals were found between good and poor images $(t(10983.665)=1.583)$. However, students exhibited higher emotional arousal to good representations $(M=.798, S D=2.259)$ than to bad representations $(M=.735$, $S D=1.942$ ) (Table I.).

To address the hypothesis and research question, a Paired $\mathrm{T}$ test was run to assess the differences in emotional arousal between good and poor representations across different design principles. Each pair of good and poor representation was highly correlated to each other $(p<.05)$. The results found image pairs $12,31,46,50$ and 54 had a significant mean difference. The image pairs 31 and 46 were relevant to principle color. The image pairs 12 and 54 were relevant to principle value.

The image pair 50 was relevant to principle orientation. The results indicated that the mean concern for image 23, which was a good value representation $(M=.399, S D=.803)$, was less than the mean concern for image 24 , which was a poor value representation $(M=.672, S D=1.455), t(103)=-2.286, p$ $<.05$. The mean concern for image 107, which was a good value representation $(M=1.001, S D=2.202)$ was greater than the mean concern for image 108, which was a poor value representation $(M=.620, S D=1.524), t(103)=2.406, p<.05$. The mean concern for image 61 which was a good color representation $(M=.546, S D=1.315)$ was less than the mean concern for image 62, which was a bad value representation $(M=1.024, S D=2.535), t(103)=-2.741, p<.05$. Another image pair 46 was indicated to color. The mean concern for image 91, which was a good color representation $(M=.503, S D=.128)$ was less than the mean concern for image 92 , which was a poor color representation $(M=.908, S D=.245), t(103)=-2.31, p<.05)$. The mean concern for image 99 , which was a good orientation representation $(M=.771, S D=1.928)$ was less than the mean concern for image 100, which was a poor orientation representation $(M=1.528, S D=4.437), t(103)=-2.14, p<. .05)$.

TABLE I. LEVENE'S TEST RESULTS OF THE INDEPENDENT0SAMPLES T TEST

\begin{tabular}{|c|c|c|c|c|c|c|c|}
\hline & \multicolumn{6}{|c|}{ Independent Sam } \\
\hline & & \multicolumn{2}{|c|}{$\begin{array}{l}\text { Levene's Test for Equality of } \\
\text { Variances }\end{array}$} & \multicolumn{4}{|c|}{ t-test for Equality of Means } \\
\hline & & $\mathrm{F}$ & Sig. & $t$ & df & $\begin{array}{l}\text { Sig. }(2- \\
\text { tailed) }\end{array}$ & $\begin{array}{c}\text { Mean } \\
\text { Difference }\end{array}$ \\
\hline & $\begin{array}{l}\text { Equal variances } \\
\text { assumed } \\
\text { Equal variances not } \\
\text { assumed }\end{array}$ & 9.982 & .002 & $\begin{array}{l}1.583 \\
1.583\end{array}$ & $\begin{array}{r}11230 \\
10983.665\end{array}$ & .113 & $\begin{array}{l}.06296156 \\
.06296156\end{array}$ \\
\hline
\end{tabular}

TABLE II. LEVENE'S TEST RESULTS OF THE INDEPENDENT SAMPLES T TEST

\begin{tabular}{|c|c|c|c|c|c|c|}
\hline \multirow[b]{2}{*}{$\begin{array}{c}\text { Design } \\
\text { Principle }\end{array}$} & \multicolumn{2}{|c|}{ Good } & \multicolumn{2}{|c|}{ Poor } & \multirow[b]{2}{*}{$t$} & \multirow[b]{2}{*}{$d f$} \\
\hline & M & SD & M & SD & & \\
\hline $\begin{array}{c}\text { Value } \\
\text { Paired } 12\end{array}$ & .4 & .8 & .67 & 1.46 & $-2.28^{*}$ & 103 \\
\hline $\begin{array}{c}\text { Value } \\
\text { Paired } 54\end{array}$ & 1 & 2.2 & .62 & 1.52 & $2.41^{*}$ & 103 \\
\hline $\begin{array}{c}\text { Color } \\
\text { Paired } 31\end{array}$ & .55 & 1.32 & 1.02 & 2.54 & $-2.74^{\bullet}$ & 103 \\
\hline $\begin{array}{c}\text { Color } \\
\text { Paired } 46\end{array}$ & .50 & .13 & .91 & .25 & $-2.31^{*}$ & 103 \\
\hline $\begin{array}{c}\text { Orientation } \\
\text { Paired 50 }\end{array}$ & .77 & 1.93 & 1.53 & 4.43 & $-2.14^{*}$ & 103 \\
\hline
\end{tabular}

$* 2<.05$.

\section{CONCUSION}

The purpose of this study was to identify an approach to the design of visual displays for online instruction that enhances positive emotions and engagement of students who are studying via online instruction. That was done by developing sequenced images which embedded different design principles to measure students' emotional arousals.

Overall, the results found student's emotional arousal were significantly different between good and bad representations for color, value and orientation. Although the findings were limited, they support the procedures of experimental design, research literature, and skin conductance measurement in online instructional design.

\section{SUGGESTIONS AND FUTURE STUdY}

This research focused on design principles, which were applied successfully by the system in the study, and 
measurement of student's emotional arousals through the skin conduct equipment. Limitations of the analyses were the individual differences and time series. The participants in the study were limited to college students. This was due to the complexity and time requirements in designing and developing the visual display designs. The study did not consider differences in learner attributes, such as gender or cultural background.

Future research is suggested by reducing the number of images and to look at more complex online lessons $\backslash$ designs not covered by this study. Also, consideration should be given to the background differences of the participants.

\section{ACKNOWLEDGMENT}

System Support provided by Tom Shorck was greatly appreciated. The project was supported by eLearning Design Lab in the Center for Research on Learning at the University of Kansas.

\section{REFERENCES}

[1] D. D. Wickens, Characteristics of word encoding, 1973.

[2] S. M. Kosslyn, "Graph design for the eye and mind." Oxford University Press, 2006.

[3] R. E. Mayer, "Learning strategies for making sense out of expository text: The SOI model for guiding three cognitive processes in knowledge construction," Educational Psychology Review, 8, pp. 357-371, 1996.

[4] D. A. Norman, and A. Ortony, "Designers and users: Two perspectives on emotion and design," In Proc. of the Symposium on Foundations of Interaction Design at the Interaction Design Institute, Ivrea, Italy, 2003.

[5] S. Weinschenk, 100 things every designer needs to know about people. Pearson Education, 2011.

[6] J. Bertin, Semiology of graphics: diagrams, networks, maps, 1983.

[7] L. V. Morris, C. Finnegan, and S. S. Wu, "Tracking student behavior, persistence, and achievement in online courses," The Internet and Higher Education, 8(3), pp. 221-231, 2005.

[8] S. Carr, "As distance education comes of age, the challenge is keeping the students," Chronicle of higher education, 46(23), 2000.

[9] D. Diaz, Online drop rates revisited. The technology source. Available online at http://ts.mivu.org/default.asp? show=article and id=981 id $=981,2002$

[10] C. Kemp, "Persistence of adult learners in distance education," The American Journal of Distance Education, 16, pp. 65 - 81, 2002.

[11] R. M. Meyer, and M. C. Meyer, "Utilization-focused evaluation: Evaluating the effectiveness of a hospital nursing orientation program," Journal for Nurses in Professional Development, 16(5), pp. 202-208, 2000 .

[12] T. Hall, N. Strangman, and A. Meyer, "Differentiated instruction and implications for UDL implementation," Retrieved September 23, 2011 from

http://aim.cast.org/learn/historyarchive/backgroundpapers/differentiated _instruction_udl, 2011.

[13] S. M. Kosslyn, "Graphics and human information processing: a review of five books," Journal of the American Statistical Association, 80(391), pp. 499-512, 1985.

[14] S. M. Kosslyn, "Understanding charts and graphs. Applied cognitive psychology,”3(3), pp.185-225, 1989.

[15] S. M. Kosslyn, (1994). Image and brain.

[16] S. M. Kosslyn, 0. KOENIG, Wet Mind: The New Cognitive Neuroscience, 1992.

[17] S. S. Stevens, Psychophysics. Transaction Publishers, 1975.

[18] M. Coe, and M. Coe, Human factors for technical communicators. New York: Wiley, 1996.

[19] S. M. Allen, and K. J. Daly, "The effects of father involvement: An updated research summary of the evidence," Centre for Families, Work and Well-Being, University of Guelph, 2007.

[20] D. J. Freeman, T. M. Kuhs, A. C. Porter, R. E. Floden, W. H. Schmidt, and J. R. Schwille, "Do textbooks and tests define a national curriculum in elementary school mathematics?" The Elementary School Journal, pp. 501-513, 1983.

[21] W. J. Popham, "Why standardized tests don't measure educational quality," Educational Leadership, 56, pp. 8-16, 1999.

[22] J. Fredricks, W. McColskey, J. Meli, J. Mordica, R. Montrosse, and K. Mooney, "Measuring student engagement in upper elementary through high school: A description of 21 instruments," Issues and Answers Report, REL, 98, 098, 2011.

[23] C. McNaught, "Quality assurance for online courses: From policy to process to improvement," In Meeting at the Crossroads, pp. 435-42, 2001

[24] P. C. Sun, R. J. Tsai, G. Finger, Y. Y. Chen, and D. Yeh, "What drives a successful e-Learning? An empirical investigation of the critical factors influencing learner satisfaction," Computers and Education, 50(4), pp. $1183-1202,2008$

[25] S. D. Johnson, S. R. Aragon, and N. Shaik, N. "Comparative analysis of learner satisfaction and learning outcomes in online and face-to-face learning environments," Journal of interactive learning research, 11(1), pp. 29-49, 2000.

[26] A. N. Meltzoff, P. K. Kuhl, J. Movellan, and T. J. Sejnowski, "Foundations for a new science of learning," science, 325(5938), pp. 284-288, 2009.

[27] K. R. Koedinger, and V. Aleven, "Exploring the assistance dilemma in experiments with cognitive tutors," Educational Psychology Review, 19(3), pp. 239-264, 2007.

[28] A. R. Damasio, The feeling of what happens: Body, emotion and the making of consciousness. Random House, 2000.

[29] P. R. Pintrich, and E. V. De Groot, "Motivational and self-regulated learning components of classroom academic performance," Journal of educational psychology, 82(1), 33, 1990.

[30] J. J. Braithwaite, D. G. Watson, R. Jones, and M. Rowe, "A Guide for Analysing Electrodermal Activity (EDA) and Skin Conductance Responses (SCRs) for Psychological Experiments," Psychophysiology, 49, pp. 1017-1034, 2013.

[31] M. Benedek, and C. Kaernbach, "Decomposition of skin conductance data by means of nonnegative deconvolution," Psychophysiology, 47(4), pp. $647-658,2010$.

[32] M. Benedek, and C. Kaernbach, "Physiological correlates and emotional specificity of human piloerection," Biological psychology, 86(3), pp. 320-329, 2011.

[33] W. Boucsein, Electrodermal activity. Springer, 2012. 